\title{
Study on the Relationship between Innovation Types and Factors Supply
}

\author{
Dongming $\mathrm{Yu}$
}

Shenyang municipal Party School, Shenyang, China;

\begin{abstract}
Keywords: Innovation type; Factors supply; Empirical study
\end{abstract}
\begin{abstract}
In the long-term follow-up study of sample enterprises, we found that the elements supply growth will bring different effects on innovation activities. Through in-depth research, the author found that, in the context of independent innovation, elements inputs will encourage enterprises to continuously improve the independent innovation activities and put a lot of effort into them. However, in the context of imitative innovation, elements inputs, can not improve independent innovation interests, but it will be input into to technical activities which are in the increasingly high degree of simulation. This study to explore the deep-seated reasons of this phenomenon, further explores the sample enterprises, and finally found between different types of innovation activities and the factors supply, has regulating effect on two-way lever, and clearly and objectively describes the mechanism as well as the process and way of interaction.
\end{abstract}

\section{Introduction}

Innovation activities are based on factors supply, and the study founds that in the sample tracking process, the impacts of factors supply on innovation activities are divided into two kinds: on the one hand, in some regions or industries, the more increase of the factor supply, the less motivation of independent innovation it leads to. Enterprises are keen to imitate, and in the process of imitation, they can make the introduction of similar products more faster, more effective and low the risks, so as to obtain high returns. That is to say, the enhancement of factor supply ability can not promote independent innovation and growth, but will support the imitation innovation to a certain extent. on the other hand, in certain regions or industries and the growth of elements supply capacity can stimulate the growth of enterprise independent innovation. Through continuous innovation to seek the disruptive market share, and the formation of siphon effect factors, namely the improvement of supply ability can provide more support for independent innovation activities, so as to make it's innovation achievements constantly updated, and achieve greater success, until the formation of leading ability in the industry. Then, the supply of factors of capacity growth, why will lead to two different innovation situation? What it will leads to as the development of these two kinds of situations on the innovation of industrial or regional economy? This study attempts to find out the factors of supply mechanism of innovation mode, effect and then answer innovation model of the industry or regional economic development.

\section{Literature Review}

\section{Research on the Relationship between Independent Innovation and Imitation Innovation}

There are many researches on independent innovation and imitative innovation in developing countries, and our research results are representative. Since the reform and opening up, Chinese scholars have made some useful explorations on how to do imitation innovation and how to play back advantage in our country. Jin Chen (1994) analyzed the relationship between the learning method and the technological innovation form of the technical catch - up process of the following countries. Peigong Shi (1999) studied the advantages of technological innovation from the point of imitation innovation, and discussed the internal mechanism of imitation innovation to produce advantage.

Since twenty-first Century, China put forward the strategy of independent innovation system. Jiaji $\mathrm{Fu}(1998)$ believes that independent innovation is a creative activity with respect to imitate 
innovation, so as to get rid of dependence on external technology, to rely on its own strength and get technology breakthrough through independent research and development activities. Two the main difference lies in the imitation innovation is in the lead innovator with intellectual property rights of science and technology on the basis of the results of the "imitation", is on the basis of the work of others in further efforts, so it can be called the "two innovation".

Independent innovation and imitation innovation are the two main strategies of technological innovation, how to balance about the relationship between them, Yuyin Yi, Zhaohan Sheng, Tiaojun Xiao (2005) hold that in certain conditions, the market will evolve into a stable state of structure, independent innovation of enterprises which have a certain proportion of the rest of the enterprise the imitation innovation

\section{Research on the influencing factors of imitative innovation}

Fu (1998) believes that the ability of imitative innovation mainly relates to the enterprises' quick response ability, learning absorption ability, technological improvement ability, mass production capacity, marketing ability and so on. Yun Song and Jinze Zeng (2007) emphasize the role of learning in improving the ability of imitation. They believe that there are four aspects of technological learning: technological trajectory, absorptive capacity, technological transfer and dynamic learning.

Most scholars focus on human capital. Nelson and Wang ( 1966 ) believe that a country's ability to introduce and use new technologies comes from the stock of human capital in the country, the higher the human capital stock, the faster the technology developed. Benhabib and Spiegel (1994), $\mathrm{Xu}$ (2000), by "critical value" of human capital affecting technological absorption capacity, show that the technology transfer effect is not obvious due to the lack of sufficient human capital to absorb advanced technology, and the effect of technology transfer in the developed countries is significant. Wei Zou, Qian Dai(2003) pointed out that one of the main reasons for the post - war East Asian economy was due to the great importance of the accumulation of human capital and the improvement of human capital level, making these countries and The region has greatly enhanced the ability of imitation and absorption of advanced technology in developed countries.

However, through the research of a large sample of the innovative activities of enterprise tracking, found in the enterprise innovation activities, only a part of the human capital factors, more such as: policy, environment, technology, capital, market, production capacity and other factors, will have an impact on the different aspects of innovation activities. The impact of these factors on the innovation activities, constitute a huge system, between the various elements of mutual restraint, mutual support, mutual influence, perplexing. This study tries to find out the relationship between innovation activities and factor systems in this complex factor system, and finally realize two-way leverage control.

\section{Research on the influencing factors of independent innovation.}

The research of technological innovation has lasted for more than half a century from an international point of view, but the research on the ability of independent innovation is relatively late, and started in 1980s. Scholars carry out research from different perspectives, such as from the perspective of innovative resources, from the perspective of organizational behavior, from the perspective of innovation process control, and so on. Typical: China business association do a survey on the independent innovation of enterprises China 500 strong science and technology results, including the main factors influencing the independent innovation of Chinese Enterprises: firstly, in the national innovation system, enterprise innovation is not the dominant position; secondly, the lack of incentive and restraint mechanisms and high-quality personnel; thirdly, there is no good atmosphere of innovation, enterprise innovation consciousness; fourthly, the corresponding policy of independent innovation is not perfect; fifthly, the intellectual property disputes, nearly half of enterprises are trapped; sixthly, the lack of communication research; sevenly, the technological innovation service system is not perfect. Feng(1995) thinks that the factors that affect the enterprise's independent innovation include enterprise scale, competition pressure, technology import, export orientation, technology proprietary and so on. [9]. Wei(2002) explored the relationship between firm size, industry concentration and independent innovation capability, 
focusing on the impact of China's manufacturing concentration on independent innovation [10].

\section{The relationship between innovation type and factors supply}

\section{Sample description.}

In reality, many enterprises (except for scientific research enterprises) are not completely independent innovation or imitate the state of innovation. In this study, we collected 435 samples (263 of the actual samples and 172 samples from the sample), and we divided our corporate innovation activities into five levels according to the share of the two types. Respectively: independent ++ (says more than $80 \%$ of the enterprise independent innovation activities), independent + (for independent innovation activities in the $60-80 \%$ of the enterprise), innovation (for independent innovation activities between 45-55\%), imitation + (said to imitate activities in $60-80 \%$ of companies), imitation ++ (for more than $80 \%$ of the enterprise independent innovation activities).

We can conclude that the model enterprises in Liaoning province are significantly behind Guangdong enterprises in their capacity of independent innovation. And the independent innovation ability of domestic enterprises lags behind that of German and American enterprises, but it has far outstripped German and American companies in copying innovation.

\section{Imitate innovation and factors supply}

Imitation innovation is to take the lead in innovation main body innovators learn innovative ideas, experience and behavior, to buy or to decipher the core technology and the technical secret, to improve and perfect the technology, according to the market characteristics and trends are further developed innovation behavior. Imitation innovation is on the basis of the original technology of learning, improve and perfect, creating, making it the first technical innovator similar or higher level, and may even replace the old technology, rather than the same kind of or reproduce the same level of technology.

In the imitation of innovation situation, the demands of enterprises towards elements tend to be homogeneous. At the same time, the cultivation and excavation of other elements are ignored. So, in this case, the more abundant of the elements supply of adaptation to innovation, the more likely it is to affect the growth and utilization of other elements. In particular, the elements that cannot be provided for independent innovation activities will naturally affect independent innovation activities.

However, due to the homogenization of the elements of enterprise demand, the factors that can meet the requirements are easy to be scarce. From another point of view, although imitation innovation can constantly improve the technical details and improve the consumer experience, it cannot radically expand the market demand. At the same time, due to the imitation innovation enterprises is to continuously optimize the supply of a product or service quality, it can cause excessive development companies in the same market demand, resulting in weak demand or capital chain rupture even excess capacity.

In this study, we can find out that in the areas where the proportion of innovation enterprises is larger than that of innovation enterprises, there will be periodic high-speed growth. However, due to the excessive development of single demand, it is also easier to have excess capacity.

\section{Independent Innovation and Conditions of Factors Supply.}

Independent innovation is a kind of innovation of relative to the imitation innovation activities, namely the innovation needed a breakthrough of the core technology comes from inside, is to get rid of technology introduction, to imitate the way dependence on external technology, to rely on their own, through independent research and development activities.

In independent innovation situation, enterprises are asked to found different market demand, and master the factors which can meet the demand, and is subject to these elements form can satisfy the demand of the product or service. At that time, demand for elements of their generation to simulate innovation more diverse, because the independent innovation has just completed, only it can provide that product or service, so the demand for production of the required elements are relatively small, compared with the independent innovation and imitation innovation degree of dependence on 
a single element is greatly reduced, and even some conditions will form part of resource elements of liberation or rescheduling. This study shows that the increase of factor supply is conducive to the growth of independent innovation under the independent innovation situation. However, because compared with the imitation innovation, innovation of higher risk, need the necessary policy support and the protection of the intellectual property law, when chooses the path of independent innovation, so enterprise will be combined with local innovation environment.

\section{Transformation of Innovation Types.}

In actual economic activity, the innovation activities of enterprises are never simply represented by a single type, including specialized agencies engaged in innovative research. Because the innovation that any enterprise involves is based on the actual product and the market, today, it is hard to imagine anything that has nothing to do with products of the past. So, independent innovation and imitation innovation are often intertwined, most of the time, independent innovation provides the technical direction for imitation innovation, and imitation innovation provides a way for the continuous improvement of the independent innovation program, even in a certain stage, intertwined with each other, always changing.

This research sample, according to a study to the enterprise in a simulated innovation after saturated, the discovery of new market demand, or drying up of the elements of the original guide enterprises to find and cultivate new elements, these elements will be energy of enterprise independent innovation. In this study, we also found that in places where independent innovation is active, imitation innovation is not very depressed, and the regional innovation structure has the dumbbell type or the class dumbbell type.

\section{The factors supply model of innovation activity.}

In the above model, the vertical axis represents the degree of innovation, and the higher the innovation content is, the greater the deviation from the original technology; On the contrary, the more you look down, the greater the resemblance is. The horizontal axis represents the growth of factor supply, because the innovation input activities cannot be 0 . Therefore, the innovation curve has no intersection with the horizontal axis. In addition, because of innovation activities, it is impossible to expand without foundation, so there is no point of intersection between the innovation curve and the vertical axis.

The factor supply model of innovation activities, clearly marked, the relationship between innovation activities and elements, and the characteristics of innovation activities themselves. Therefore, the factors supply model of innovation activities proposed in this study is very helpful to research the factors driving relationship of innovation activities and the connotation of innovation activities under different scenarios.

\section{The application value of innovation activity and factors supply relationship research}

\section{The function and flow of imitative innovation}

When the market is obvious to a certain demand and there have been appeared relatively mature solutions, at this time, it can provide the market with more production capacity, ameliorative R\&D capability and so on and can promote the rapid growth of imitation innovation activities in the region. On the micro level, it can quickly irritate the rapid growth of companies in this industry and complete original accumulation. On the medium level, it is conducive to formation the industrial chain based on production capacity. On the macro level, it can speed up ascend the regional economic vitality and in order to form industry agglomeration laid the foundation.

There are also some negative effects in this way and forms three development traps on the supply side. The first trap emerged when local demand tends to be saturated. If we cannot form an orderly supply output, it will form a disordered vicious competition, leading to supply early stage of low-cost competition. The quality of the product is lowered with cost decline finally exits the market. The second trap is that before the supply of local elements tends to be saturated. There is no adjustment to the product technical solution, which still relies too much on the original elements. As the elements are about to dry up, causing the cost of elements increases and the cost of local enterprises increases. Eventually causes products in the field which at a low price to enter the local 
market and local market exit. The third trap is the local resources to increase the supply of elements needed to support specific product production, then causing single product development supported by elements. There out, it will cause a demand market to be overexploited and then lead to weak demand and excess production capacity.

\section{The role and dilemma of independent innovation.}

Independent innovation is the main mode of innovation. It often promotes the formation of new market demand at the same time forms a different element support structure. It can not only get rid of the constraints of the structural lack of elements, but also seek more ideal profit space. At the same time, it can promote the growth of other related technologies in the industrial chain. It is also helpful to form a non-resource-dependent regional economic structure. Therefore ,most countries and regions strongly advocate and support independent innovation from the perspective of long term development.

Compared to the imitation innovation, the independent innovation and development time is long and the input cost is high, at the same time the recovery risk is large. Once the lack of policy protection or following the innovation to achieve technological breakthrough, it will greatly affect the enterprise innovation benefit. These shortcomings often affect entrepreneurs' enthusiasm for independent innovation.

\section{The Solution of This Study.}

This study claims that study on the contribution of innovation types should be based on reality. Depending on the regional economy and the different state of the market, we support its selection of different types of innovation. At the same time according to the specific performance of the operation process and the factor demand and influence, the mode of factor supply and factor structure is adjusted timely. In this way the mutual transformation and scientific integration of the innovation situation are promoted, eventually the benign regional economic development model is formed.

For example, in imitation of innovative situations, we should encourage healthy competition of enterprises while promoting capacity accumulation and effectively guides the output of production and technology diffusion. Once there is a vicious competition, we need promote the enterprise transformation and upgrading early and drive the market with self-service innovation. In addition from the perspective of promoting healthy competition in the market and protecting innovation environment. The government needs to protect the intellectual property rights of indigenous innovation; making independent innovation can get the expected return and promoting entrepreneurs actively participate in independent innovation. At the same time, the necessary measures should be taken to encourage appropriate technology diffusion. Technical secondary development and imitation innovation to make up for the lack of original technology. In this way, it can provide effective means for the diffusion of technology and add new impetus to regional economic development.

\section{References}

[1] J. Chen, From Technology Introduction to the Study Mode of Independent Innovation,Scientific Research Management, 3(1994)32-34. (In Chinese)

[2] Y.Y. Yi, Z.H. Sheng and T.J. Xiao, Research on Independent Innovation and Imitation Innovation and Market Structure Evolution, Journal of Management Engineering, 1(2005)14-18. (In Chinese)

[3] Y. Song and J.Z. Zeng, Research on Evolutionary Path from Imitation Innovation to Independent Innovation, Modern Management Science, 5(2007)36-39. (In Chinese)

[4] Nelson and Phelps, Investments in Humans, Techno-logical Diffusion and Economic Growth, American Eoconomic Review, 65(1996)69-75.

[5] Benhabib and Spiegel, The Roles of Human Capital in Economic Development: Evidence from Aggregate Cross-country Data, Journal of Monetary Economics, 34(1994).

[6] W. Zou and Q. Dai, Technological Imitation, Human Capital Accumulation and Economic Catch-up, Chinese Social Sciences, 5(2003)26-38. (In Chinese) 
[7] F. Feng, Several Basic Factors that Influence the Behavior of R\&D in Technological Innovation Activities, China Soft Science, 10(1995). (In Chinese)

[8] H.K. Wei, Enterprise Scale, Industrial Concentration and Technological Innovation Ability, Economic Management, 4(2002). (In Chinese)

[9] S.P. Li, Lack of Dynamic Innovation of Enterprise Technology in China: Game Analysis of Reasons and Countermeasures, Economic Research of Nankai, 3(2009)116-127. (In Chinese) 